\title{
First look at LSD in action reveals acid-trip biochemistry
}

Studies reveal drug's crystal structure and how it affects people's perceptions of meaning.

Amy Maxmen

26 January 2017

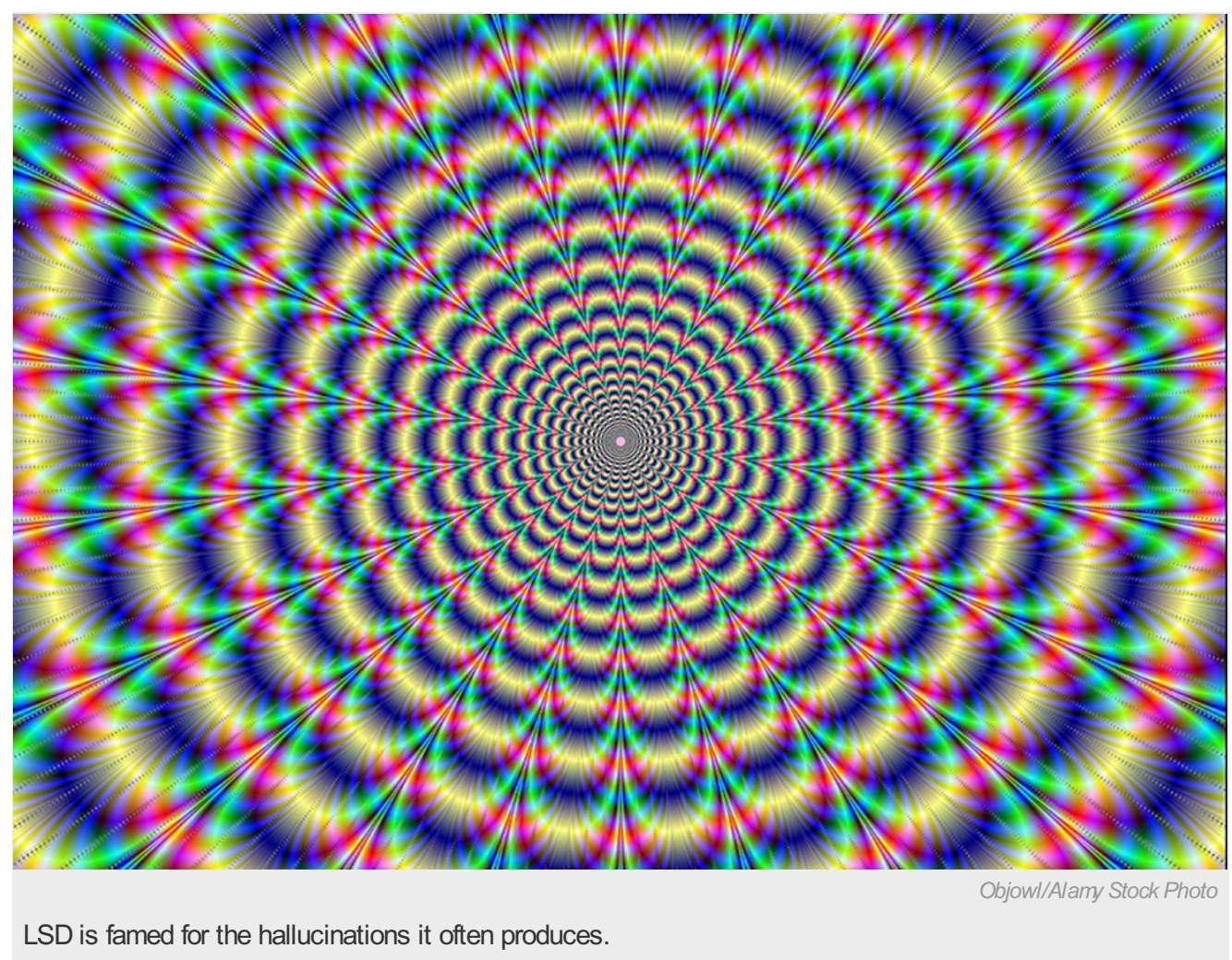

The acid tests of 1960s San Francisco have morphed into something quite different in today's Silicon Valley. Mind-altering trips have given way to subtle productivity boosts purportedly caused by tiny amounts of LSD or other psychedelic drugs. Fans claim that this 'microdosing' boosts creativity and concentration, but sceptics doubt that ingesting or inhaling one-tenth of the normal dose could have an effect.

Science could soon help to settle the matter. Researchers have finally mapped the 3D structure of LSD in its active state — and the details, published today in Cell ${ }^{1}$, indicate the key to the chemical's potency ${ }^{1}$. Another team reports today in Current Biology ${ }^{2}$ that it has pinpointed the molecular go-between that creates the perception of deep meaning experienced during acid trips - a feeling that the writer Aldous Huxley once described as "solidarity with the Universe".

"This is what we dreamed of doing when I was a graduate student in the seventies," says Gavril Pasternak, a pharmacologist at Memorial Sloan Kettering Cancer Center in New York City who has spent decades studying the receptor proteins in the brain that mediate the activity of opioids and psychedelic drugs. "Work like this expands our understanding of how these receptors work."

\section{A long, strange trip}

In 1972, researchers revealed LSD's shape by mapping the arrangement of atoms in its crystallized form ${ }^{3}$. But in the decades since, they've struggled to reveal the crystal structure of a receptor grasping a molecule of LSD or another psychedelic drug. This active configuration is key to understanding how drugs work, because their action depends on how they cling to molecules in the body.

Now, the team behind the Cell study has shown how LSD binds to the protein $5-\mathrm{HT} 2 \mathrm{~B}$, a receptor for the neurotransmitter serotonin, which helps regulate activities such as appetite and mood. "This is the first picture of a psychedelic drug in action," says lead author Bryan Roth, a pharmacologist at the University of North Carolina at Chapel Hill.

Roth was surprised to discover that the receptor includes a lid-shaped structure that hovers over the LSD molecule, and that the drug 
apparently triggers the lid to close, trapping the molecule inside the receptor. "Imagine a person crawling into a manhole and a cover sliding over them so they can't get out," he says.

The lid seems to explain why LSD's effects can last for more than 20 hours, depending on the amount taken. It also supports the idea that microdosing can have an effect, even when people take doses that are less than one-tenth of the normal amount. "The fact that LSD gets trapped provides an explanation for why extremely small amounts of the drug can still be potent," Roth says. "Before this, what I heard from Silicon Valley was purely anecdotal."

His study did not reveal how microdosing affects people in the short or long term. But another group — led by Katrin Preller, a psychopharmacologist at the University Hospital for Psychiatry Zurich in Switzerland - examined the root of certain acid experiences in a study of 22 healthy university students.

Preller was interested in the biological basis of one aspect of tripping that involves the assignment of 'meaning', which is based on personal relevance. "If you have a spider phobia, then the sight of a spider is meaningful," Preller says. "But if you don't have a phobia it doesn't trigger much within you."

\section{The sound of music}

Preller's team asked study participants to list songs that were personally meaningful to them. Then each person was randomly given LSD, a placebo or LSD with ketanserin, a drug that stops LSD from binding to a serotonin receptor similar to 5-HT2B. Importantly, ketanserin does not prevent LSD from connecting to other proteins, such as dopamine receptors or adrenoreceptors.

Soon after the dose, the participants heard clips from their chosen tunes, similar songs and free jazz, which almost none of them had previously considered meaningful. They rated each clip in terms of whether the song felt meaningful, pleasant and connected with them. Free jazz elicited substantial emotions only in those who had taken LSD without ketanserin.

Likewise, only the students in the LSD group reported strong feelings of unity, bliss and disembodiment, and of seeing sounds or hearing colours, after taking their treatments. Because the ketanserin negated those perceptions, Preller's team concluded that the serotonin receptor controls the perception of meaning under the influence of LSD, and perhaps beyond.

Preller hopes that the finding will trigger research on drugs to treat symptoms of schizophrenia that stem from a dysfunctional assignment of meaning — such as the paranoia that occurs when an individual interprets an irrelevant object or person as dangerous.

And knowing the crystal structure of LSD could aid researchers who are trying to design drugs that mimic some psychedelic compounds' ability to alleviate depression, but spare them paranoia and debilitating hallucinations.

"We desperately need new drugs in psychiatry," Preller says, "so all of this work is important."

Nature | doi:10.1038/nature.2017.21377

\section{References}

1. Wacker, D. et al. Cell http://dx.doi.org/10.1016/j.cell.2016.12.033 (2017).

2. Preller, K. H. et al. Curr. Biol. http://dx.doi.org/10.1016/j.cub.2016.12.030 (2017).

3. Baker, R. W., Chothia, C., Pauling, P. \& Weber, H. P. Science 178, 614-615 (1972). 